\title{
Advancing Liquid Metal Reactor Technology with Nitride Fuels
}

\section{DO NOT MIRROFLM \\ COVER}

Prepared for the U.S. Department of Energy Assistant Secretary for Nuclear Energy

\section{Q Westinghouse \\ Hanford Company Richland, Washington}

Hanford Operations and Engineering Contractor for the

U.S. Department of Energy under Contract DE-AC06-87RL10930

Copyright License By acceptance of this article, the publisher and/or recipient acknowledges the U.S. Government's right to retain a nonexclusive, royalty-free license in and to any copyright covering this paper. 


\section{DISCLAIMER}

This report was prepared as an account of work sponsored by an agency of the United States Government. Neither the United States Government nor any agency Thereof, nor any of their employees, makes any warranty, express or implied, or assumes any legal liability or responsibility for the accuracy, completeness, or usefulness of any information, apparatus, product, or process disclosed, or represents that its use would not infringe privately owned rights. Reference herein to any specific commercial product, process, or service by trade name, trademark, manufacturer, or otherwise does not necessarily constitute or imply its endorsement, recommendation, or favoring by the United States Government or any agency thereof. The views and opinions of authors expressed herein do not necessarily state or reflect those of the United States Government or any agency thereof. 


\section{DISCLAIMER}

Portions of this document may be illegible in electronic image products. Images are produced from the best available original document. 


\section{Advancing Liquid Metal Reactor Technology with Nitride Fuels}

W. F. Lyon

R. B. Baker

R. D. Leggett

Westinghouse Hanford Company

R. B. Matthews

Los Alamos National Laboratory

Date Published

August 1991

To Be Presented at

International Conference on

Fast Reactors and Related Fuel Cycles

Kyoto, Japan

October 28 - November 1, 1991

Prepared for the U.S. Department of Energy

Assistant Secretary for Nuclear Energy

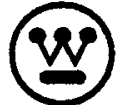

Westinghouse

Hantord Company Richland, Washington 99352

Hanford Operations and Engineering Contractor for the

U.S. Department of Energy under Contract DE-AC06-87RL10930

Copyright License By acceptance of this article, the publisher and/or recipient acknowledges the U.S. Government's right to retain a nonexclusive, royalty-free license in and to any copyright covering this paper.

Approved for Public Release

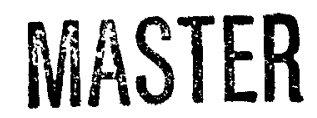




\title{
ADVANCING LIQUID METAL REACTOR
}

\section{TECHNOLOGY WITH NITRIDE FUELS}

\author{
W. F. Lyon* \\ R. B. Baker* \\ R. D. Leggett* \\ R. B. Matthews**
}

ABSTRACT

A review of the use of nitride fuels in liquid metal fast reactors is presented. Past studies indicate that both uranium nitride and uranium/plutonium nitride possess characteristics that may offer enhanced . performance, particularly in the area of passive safety. To further quantify these effects, the analysis of a mixed-nitride fuel system utilizing the geometry and power level of the U.S. Advanced Liquid Metal Reactor as a reference is described.

\section{INTRODUCTION}

The purposes of this paper are to (1) summarize the past experiences and the present activities with the development of nitride fuels for liquid metal reactors (IMR), (2) identify key performance issues, (3) recommend specific design criteria, and (4) summarize conceptual design studies currently underway at Westinghouse Hanford Company (WHC). This study is prompted by an interest in alternative fuel designs for advanced LMRs with an emphasis on enhanced performance and passive safety.

Past fuel development programs have encompassed a wide spectrum of fuel types and designs including oxide, binary and ternary metal, carbide, and nitride fuels. However, today there is a gradual international concensus evolving that nitride fuels may represent an option for future development as an advanced fast reactor fuel. This is due to the belief that nitride fuel systems may offer an improvement in the safety performance of IMRs. A general summary of the characteristics of nitride fuels and their impacts on LMRs is illustrated in Table 1 . The potential advantages of the use of nitride fuels in LMRs were summarized nearly 20 years ago. 1 Today, this potential is being reassessed in terms of increasing safety performance.

\footnotetext{
* Westinghouse Hanford Company

P. O. Box 1970 MSIN L5-02, Richland, washington 99352 USA

* Los Alamos National Laboratory

P. O. Box 1663 MS E505, Los Alamos, New Mexico 87545 USA
} 
The goal of early investigations into fast reactor fuel designs centered around the development of high density, heavy metal fuels. The high heavy metal density was needed to provide enhanced core breeding (to limit large reactivity swings due to long fuel residency) and thermal performance. During the late $1950^{\prime} \mathrm{s}$, development of binary and ternary metal alloys of uranium and uranium-plutonium was undertaken to address these needs. However, despite much progress, by the early 1960's concerns over fission gas swelling and low melting point, eutectic formation prompted a gradual decline in the interest in metal fuels.

TABLE 1. Nitride Fuel Characteristics

\begin{tabular}{|l|l|}
\hline \multicolumn{1}{|c|}{ Characteristic } & \multicolumn{1}{c|}{ System Impact } \\
\hline $\begin{array}{l}\text { High thermal conductivity and } \\
\text { to metal fuels }\end{array}$ & $\begin{array}{l}\text { High power density, high thermal } \\
\text { performance, good core breeding, low } \\
\text { reactivity swings, and long residency } \\
\text { times as compared to oxide fuels }\end{array}$ \\
\hline $\begin{array}{l}\text { Fuel, cladding, and coolant } \\
\text { compatibility }\end{array}$ & $\begin{array}{l}\text { Post-breach operation possible, } \\
\text { minimal fuel/cladding chemical } \\
\text { interaction, allows use of sodium bond }\end{array}$ \\
\hline $\begin{array}{l}\text { Low sodium void coefficient } \\
\text { coefficient similar to oxide } \\
\text { fuels }\end{array}$ & $\begin{array}{l}\text { Enhanced safety performance due to } \\
\text { higher margins to failure, excellent } \\
\text { tolerance for loss of flow and } \\
\text { transient overpower without scram as } \\
\text { compared to metal fuels }\end{array}$ \\
\hline $\begin{array}{l}\text { Low fission gas release and } \\
\text { fuel swelling }\end{array}$ & $\begin{array}{l}\text { Short plenum and pins, low cladding } \\
\text { stresses, longer pin lifetime, and } \\
\text { better economics }\end{array}$ \\
\hline Eabrication and reprocessing & $\begin{array}{l}\text { Compatibility with mixed oxide } \\
\text { fabrication and reprocessing, and } \\
\text { potentially, pyro-reprocessing } \\
\text { technology - sodium bond and }\end{array}$ \\
production add complexity
\end{tabular}

Researchers then turned to ceramic fuels such as uranium- and uraniumplutonium oxides, carbides, and nitrides. Because of its well characterized irradiation performance and demonstrated fabricability, oxide fuel became the reference fuel system in practically all fast reactors despite. drawbacks associated with chemical interaction with liquid metal coolants and lower breeding capability. From the middle 1960's to the middle 1980's, advanced fuel development concentrated on carbide fuel because of its attractive nuclear and mechanical properties and compatibility with liquid metal coolants. A limited amount of work was also performed with nitride fuels, however, it was not emphasized because of early difficulties in fabrication, slightly lower breeding potential due to parasitic neutron absorption by $14 \mathrm{~N}$, and postirradiation handling difficulties with ${ }^{14} \mathrm{C}$. Further work with carbide fuels declined with the decreasing interest in the U.S. with liquid metal fast breeder reactors (LMFBR), which eventually led to the cessation of carbide fuel development. 
In the early 1980's, interest in metallic fuels was renewed in the U.S. to take advantage of its benefits and develop methods to eliminate its past perceived disadvantages. The current U.S. Advanced Liquid Metal Reactor (ALMR) core design uses the latest evolution of metal fuel and blanket designs as supported by the Integral Fast Reactor concept. 2 Outside the U.S., researchers are reconsidering the development of nitride fuels for LMFBRs. When compared to carbide fuels, nitrides offer very similar irradiation performance, better chemical stability, and easier dissolution in the head end of the plutonium/uranium extraction (PUREX) process. The advent of demonstrated fabrication techniques combined with the other advantages discussed in this paper allow nitride fuels to be viewed by LMR designers as a very viable fuel form. The attributes of nitride fuels related to economy and safety may result in a more economically competitive reactor system.

\section{NITRIDE FUEL DEVELOPMENT}

By combining many of the favorable properties of both ceramic and metal fuels, such as high operating temperatures and favorable sodium void worths (similar to oxide fuels), high thermal conductivity, high breeding ratio, and low burnup reactivity swings (similar to metal fuels), nitride fuel systems may offer significant advantages over other fuel types for application in IMRs. The recognition of this is illustrated by the variety of nitride fuel development programs emerging throughout the world.

\section{A. The United States}

Although current programs are focused on advanced metal fuels development, the U.S. has investigated the use of nitride fuels as a part of two distinct programs within the recent past. The first was the Advanced LMFBR Fuels Development Program (1974-1980). 3 This program included the irradiation of approximately 100 helium and sodium bonded $(\mathrm{U}, \mathrm{Pu}) \mathbf{N}$ pins in the Experimental Breeder Reactor - II (EBR-II). 4 It investigated a variety of testing parameters and pin geometries including pins with and without fuel shrouds (thin-walled, slotted stainless steel tubes surrounding the fuel pellets used to prevent the relocation of fuel fragments and reduce the possibility of mechanical interaction with the cladding). Pin parameters included theoretical smeared densities of $75-86 \%, 304$ and 316 stainless steel cladding, peak linear powers of 67 $107 \mathrm{~kW} / \mathrm{m}$, and peak burnups of 9 at. $\%$. The primary results of these tests indicated excellent performance by sodium bonded fuel pins. The study also observed that the performance of unshrouded pins, while similar to that of the shrouded pins, could be greatly improved by increasing cladding strength and maintaining smeared densities $\leq 80 \%$. (Based on this data set, it is proposed by the authors that lower linear powers and fuel temperatures can greatly reduce fuel cracking and thus preclude the use of fuel shrouds.) Low fission gas release rates and a lack of chemical interaction with the cladding and shrouds were also observed.

Current nitride fuel development activities are supported by the SP-100 Space Nuclear Power Program. ${ }^{5}$ This project began in 1984 and, after significant review, has selected UN utilizing refractory metal alloy cladding as the fuel system for the SP-100 reactor. The fuel pins are designed to operate at very high temperatures $\left(>1125^{\circ} \mathrm{C}\right.$ cladding temperatures) for long durations (up to seven years). Irradiation testing of UN fuel pins is continuing in the Fast Flux Test Facility (FFTF) and the EBR-II. 6 Although not directly applicable to LMFBR fuels development, the high temperature irradiation performance of these pins illustrates that the technology necessary for the development of a robust nitride fuel pin is 
readily achievable. No UN pin failures have been seen in tests conducted in the FFTF or the EBR-II. These tests have also driven the development of fabrication techniques for high theoretical density, low impurity nitride fuel pellets in the U.S.

\section{B. The European Community}

Beginning in the mid $1980^{\prime}$ 's, a European Community (EC) collaborative effort between the Commissariat à l'Energie Atomique (CEA) in Cadarache, the Institute for Transuranium Elements (ITU) in Karlsruhe, and the PaulSherrer-Institute (PSI) in Würenlingen was initiated to compare mixednitride, carbide, and oxide fuels for use in advanced IMRs. 7 The compatibility of (U,Pu)N with the conventional IMR fuel cycle already in place is a key issue for the EC. As a result, the current activities encompass the entire nitride fuel cycle:

- fabrication in both (U,Pu) $\mathrm{O}_{2}$ dry-route and sol-gel process lines

- irradiation performance up to high burnups

- $\quad(U, P u) N$ reprocessing with the PUREX process.

The results of the fabrication studies reveal that high purity (U, Pu)N can be produced by either of the two processes investigated. The CEA and ITU have produced (U,Pu) f fuel pellets via carbothermic reduction and nitriding. 6 The PSI is concentrating on a gelation process which has demonstrated the production of both ( $U, \mathrm{Pu}) \mathrm{N}$ pellets and microspheres. Irradiation testing consists of two tests in the phenix reactor containing several helium bonded (U,Pu)N pins. A third test is being planned which will include sphere-pac (U,Pu)N pins from the PSI. Parameters used in these tests include theoretical smeared densities of $75-78$ 음, cold worked, titanium stabilized stainless steel cladding, peak linear powers of $40-70 \mathrm{~kW} / \mathrm{m}$, and goal peak burnups of $15 \mathrm{at.} \%$. Interim examination of the pins from the initial test (at 7.5 at. 8 burnup) indicate very good performance. Measured cladding diametral strains are below $30 \mu \mathrm{m}(0.46 \%)$. Several of these pins will be retained for destructive examination and transient testing.

Dissolution testing required for the reprocessing of (U, Pu) N has been completed with unirradiated, $20 \%$ plutonium enriched, mixed-nitride fuel. $(\mathrm{U}, \mathrm{Pu}) \mathrm{N}$ dissolves rather quickly in $\mathrm{HNO}_{3}$, reaching complete dissolution in less than one hour. The separation of plutonium from the waste stream is also highly successful. 6 Further testing is planned with irradiated $(\mathrm{U}, \mathrm{Pu}) \mathrm{N}$ fuel pins when they become available from the irradiation testing program.

\section{Other Programs}

In addition to the programs in the U.S. and the EC, nitride fuels development is being undertaken in the U.S.S.R., Japan, and India. The Soviets have gained extensive experience with nitride fuels by testing an entire core load of UN in the BR-10 reactor. 8 Additional tests of carbide and carbo-nitrides have been irradiated in the BOR-60 reactor. The UN fuel in the BR-10 reactor reached 8.3 at. 8 burnup while pins tested in BOR-60 achieved greater than 10 at. $\%$ burnup. Testing parameters such as smeared densities and linear powers are similar to those seen in previous tests. Both Japan and India have also expressed an interest in nitride fuels. Specifically, the Japan Atomic Energy Research Institute has fabricated $(\mathrm{U}, \mathrm{Pu}) \mathrm{N}$ from $\mathrm{UO}_{2}$ and $\mathrm{PuO}_{2}$ feed materials utilizing carbothermic reduction in a mixed gas stream of $\mathrm{N}_{2}-8 \% \mathrm{H}_{2} \cdot{ }^{9}$ Work at the Bhabha Atomic Research Center in India has concentrated on (U,Pu) $\mathrm{N}$ fabrication and out-of-pile characterization. 10 As with the Europeans, the Japanese and Indian 
interest in nitride fuels stems from high performance coupled with fabrication and reprocessing compatibility with mixed-oxide technology.

\section{NITRIDE FUEL PERFORMANCE ISSUES}

The results of testing and analyses to date provide favorable expectations for the performance of nitride fuels. However, the relatively limited experience with this fuel type indicates that nitride fuels are in a low stage of maturity. Several issues exist concerning the use of nitride fuels, including fabrication, steady state and transient performance, high temperature dissociation, and reprocessing. However, as evidenced by the development programs mentioned previously, nitride fuels are beginning to be characterized at an accelerating rate.

Initially problematic, the production of a variety of nitride fuel types is no longer a technological issue. The early difficulties associated with UN fabrication have been overcome in laboratory-scale production lines. Ongoing tests in support of the SP-100 program require the production of high-quality uN pellets with theoretical densities of 95\%, low open porosity $(\sim 10 \%)$, low impurity levels, and controlled stoichiometry. This technology is now well established with the pilot plant production of UN fuel pellets by carbothermic reduction, nitriding, cold pressing, and sintering at Los Alamos National Laboratory.11 Similar work in Europe and Japan illustrates that (U,Pu) $N$ can be fabricated with a nearly identical process. 7,9 Fabrication in the laboratory is one thing, but large scale production suitable for commercial applications is quite another. The French have successfully begun addressing this aspect of fabricability by producing (U,Pu) $\mathrm{N}$ in a conventional (U,Pu) $\mathrm{O}_{2}$ line with little modification. 12 Given this, $(U, P u) N$ pilot line production technology appears to be readily transferable to large scale, fabrication facilities.

One of the more limited areas of nitride fuels development is irradiation testing. Even with the combination of historical work and the renewed testing activities outlined previously, the narrow scope of nitride fuels irradiation data represents a stumbling block to potential near-term applications. However, this can be mitigated by taking advantage of the similarity between nitride and carbide fuels. By contrast, the steady state and transient irradiation performance of carbide fuels is well established.13,14 Because of similar properties and characteristics (the primary differences are lower fuel/cladding interaction and swelling rates for nitride fuels), the carbide database can be used to establish performance trends for nitride fuels. This allows the data available for nitride fuels to be leveraged until the results of further testing are available. Based on this premise, swelling rates of $0.5 \% \Delta \mathrm{D}$ per at. $\frac{\sigma}{7}$ burnup, fission gas release rates of $1 \%$ per at. $z$ burnup, and burnups greater than 20 at. $\frac{8}{8}$ should be readily achievable by nitride fuels.

Another issue concerning the use of nitride fuels is high temperature dissociation. UN has exhibited the tendency to dissociate to free uranium and $\mathrm{N}_{2}$ at high temperatures. However, studies have shown, that this can be suppressed by controlling stoichiometry and by keeping operating temperatures below $1650 \mathrm{~K}$. Additionally, although typically viewed as a liability, dissociation may be advantageous when considering processes to convert $(\mathrm{U}, \mathrm{Pu}) \mathrm{N}$ to metal for potential pyro-reprocessing.

As stated above, the reprocessing of nitride fuels is compatible with the head end of the PUREX process. However, a concern exists that the production of ${ }^{14} \mathrm{C}$ from $(n-p)$ reactions with ${ }^{14_{N}}$ will impose design 
restrictions on reprocessing facilities. Two possible solutions include enriching the fuel with ${ }^{15} \mathrm{~N}$ to reduce the production of ${ }^{14} \mathrm{C}$ (this has also been proposed to increase breeding performance) or modifying facilities to trap effluent $\mathrm{CO}_{2}$ streams. Regardless of the method employed, the reprocessing of nitride fuels is not considered to be a serious issue.1,15

\section{RECOMMENDATIONS FOR DESIGN CRITERIA}

Based on the properties of nitride fuels along with a review of the available literature, an understanding of the performance of these fuels has been developed. Guidelines for the use of nitride fuels should both accommodate limitations as well as take advantage of favorable characteristics. After a thorough review of the available information, the following are recommended for design criteria for nitride fuel in an advanced LMR:

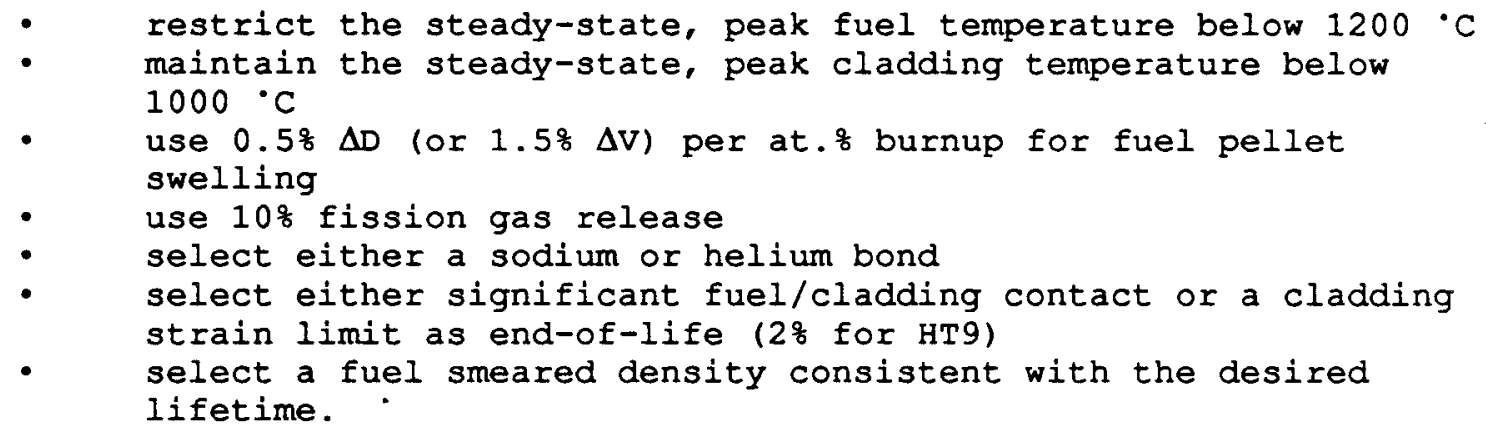

The fuel and cladding temperatures listed are conservative restrictions imposed for a variety of reasons including the elimination of the onset of fuel dissociation, fuel cracking and relocation, and possible fuel/cladding chemical interaction. This should also eliminate the need for fuel shrouds. Using a nominal $10 \%$ fission gas release simplifies calculations, however, if a more detailed correlation is desired, a value of $1 \frac{\%}{\%}$ per at. 8 burnup is supported in the literature. The use of a sodium bond will complicate fabrication and reprocessing; however, thermal performance with larger gap conductances is greatly improved. Fuel swelling is considered isotropic and would result in some axial as well as radial growth. Excessive axial growth can present problems, however, for nitride fuels, axial swelling will occur over the lifetime of the fuel pin, as opposed to the rapid, initial swelling observed in metal fuels early in life. Final axial growth will probably be similar to that observed in stainless steel clad, mixed-oxide fuel in FFTF (e.g., 5s at 100MWd/kgM). The nominal smeared density should be approximately $80 \%$ or less. It is judged that applying the above criteria will provide a rugged fuel pin design capable of very high burnup in an advanced LMR with excellent safety margins.

\section{NITRIDE FUEL ANALYSES}

To form a basis of comparison, a series of studies have been undertaken at wHC to evaluate the performance of a conceptual nitride fuel design in an advanced LMR. The U.S. ALMR was chosen as a reference. The ALMR is a modular reactor system designed to emphasize passive safety. It is sodium cooled with a ternary metal driver fuel $(\mathrm{U}-\mathrm{Pu}-\mathrm{Zr}$ ) and a binary metal blanket $(U-Z r)$. An oxide fuel cycle is designated as the alternate fuel system. Each reactor module is rated at $471 \mathrm{MWt}$. The proposed nitride fuel design consists of $(\mathrm{U}, \mathrm{Pu}) \mathrm{N}$ driver fuel with UN blankets based on the above criteria in the geometry specified for the ALMR (the nitride 
fuel and blanket pin smeared densities are somewhat higher). A list of both the blanket and nitride fuel system designs is shown in Table 2.

TABLE 2. Summary of ALMR Fuel System Designs

\begin{tabular}{|l|c|c|c|c|}
\hline \multirow{2}{*}{} & \multicolumn{2}{|c|}{ Driver Fuel } & \multicolumn{2}{c|}{ Blanket Fuel } \\
\cline { 2 - 5 } & U-Pu-10 $\mathrm{zr}$ & (U,Pu) N & U-10 Zr & UN \\
\hline Pin Length (m) & 4.267 & 4.267 & 4.267 & 4.267 \\
Active Core Height (m) & 1.3462 & 1.3462 & 1.3462 & 1.3462 \\
Cladding Material & HT9 & HT9 & HT9 & HT9 \\
Pin O.D. (mm) & 6.680 & 6.680 & 12.090 & 12.090 \\
Cladding Thickness (mm) & 0.508 & 0.457 & 0.559 & 0.508 \\
Pellet Diameter (mm) & 4.902 & 5.283 & 10.117 & 10.668 \\
Gap (mm) & 0.762 & 0.483 & 0.856 & 0.406 \\
Slug/Pellet Density (\%TD) & 100 & 95 & 100 & 97 \\
Smeared Density (\%TD) & 75 & 80 & 85 & 90 \\
Density* (g/cm ${ }^{3}$ ) & 15.8 & 14.3 & 16.0 & 14.3 \\
Wire Wrap Diameter (mm) & 1.295 & 1.295 & 0.813 & 0.813 \\
Wire Wrap Pitch (m) & 0.305 & 0.305 & 0.305 & 0.305 \\
Bond & sodium & sodium & sodium & sodium \\
Pins Per Assembly & 331 & 331 & 127 & 127 \\
\hline
\end{tabular}

* at room temperature

The results of initial studies predict that a (U, Pu) N fuel system should provide larger steady-state operating margins for fuel, blanket, and cladding peak temperatures and cladding strain when compared to the reference ternary metal fuel system in the ALMR. 16 Additional work comparing the safety performance of several fuel types as driver fuel in the FFTF indicates that a sodium bonded, $(U, \mathrm{Pu}) \mathrm{N}$ fuel system would also have the best overall transient performance compared to oxide, mixed-oxide and binary metal fuel core designs. 17 Although not included in this study, it is believed that the transient performance of ternary metal fuels would be better than mixed-oxide but still lag sodium bonded, mixed-nitride. Further refinements in the initial ALMR nitride design in the form of updated reactor physics and fuel performance calculations are complete. They include modifying cross-section sets, calculating corrected energy deposition and linear powers, in-core flow orificing, and adding hot channel factor analyses. The results of these calculations indicate improvements in the +2 sigma and nominal peak results shown in the initial calculations with the exception of slight increases in cladding strain. Plots of the results of the updated nitride fuel and blanket analyses are shown in Figures 1 and 2 .

In addition to enhanced thermal performance, physics analyses indicate that due to a complex combination of mechanisms including slowing down power, spectral hardening, and neutron leakage, the nitride fuel system exhibits lower sodium void reactivity worth than the reference ALMR ternary metal fuel system. ${ }^{18}$ The reduction of sodium void worth using nitride 
fuels is also predicted in the literature. 1 The reference ALMR nitride fuel system is calculated to have a full core, sodium void worth of $\$ 2.32$, considerably less than that of the ALMR reference metal fuel system at approximately $\$ 4$ to $\$ 6$. The emphasis of the most recent wHC work on nitride fuels is to further reduce the sodium void worth by decreasing the active fuel height while holding the core radius and power constant. This results in increasing the power density of the core. The analysis of this modified ALMR nitride design has now become a trade study balancing thermal performance (using up the available thermal margin) while decreasing the sodium void worth.

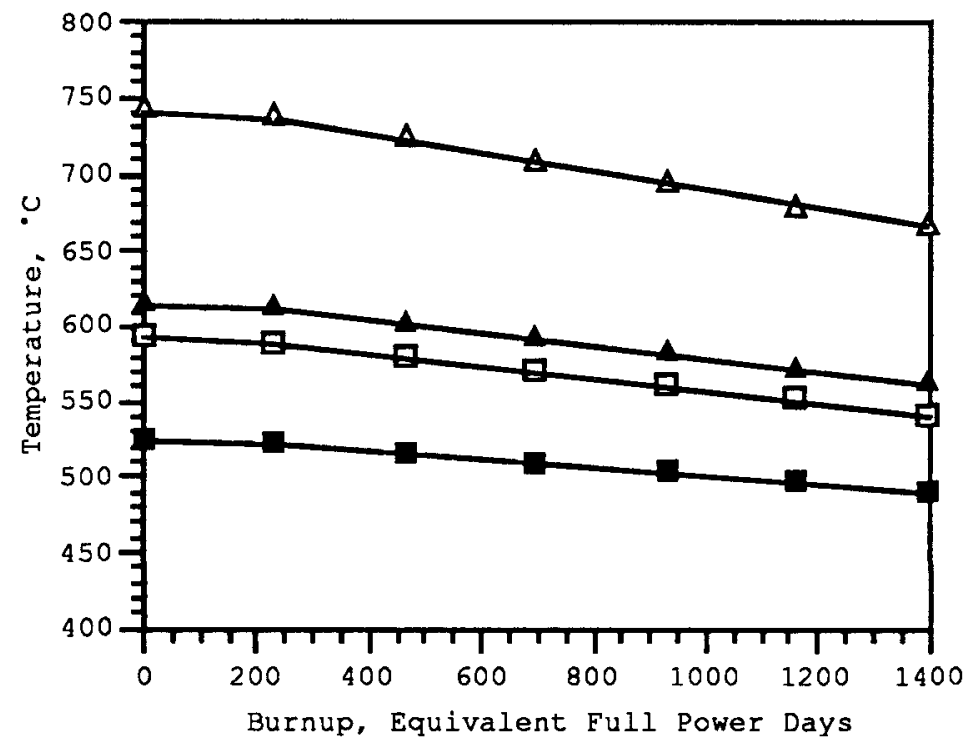

Peak

Nominal

Cladding

Midwall

Peak

Nominal

Fuel

Centerline

+2 Sigma

Cladding

Midwall

+2 Sigma

$\Delta$ Fuel

Centerline

Figure 1. (U, Pu)N Driver Fuel Temperatures

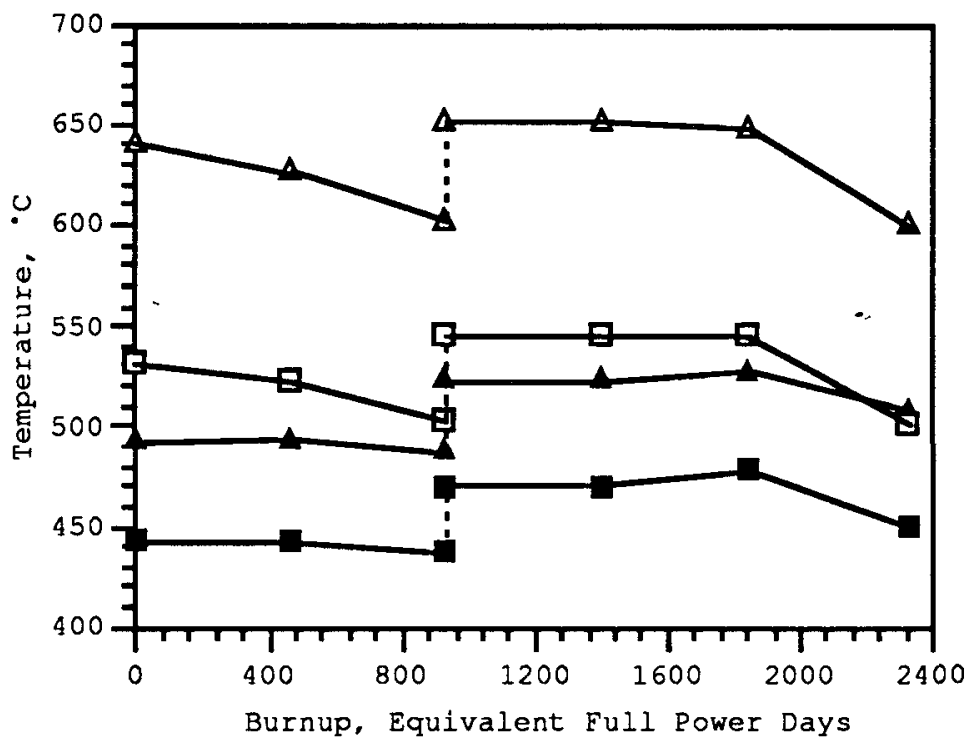

Peak

Nominal

Cladding

Midwall

Peak

Nominal

Fuel

Centerline

+2 Sigma

D Cladding

Midwall

+2 Sigma

$\Delta$ Fuel

Centerline

Figure 2. UN Blanket Temperatures

(dashes indicate shuffling of blanket pins from inner to radial positions) 
A preliminary assessment of the reduced sodium void nitride design shows that a reduction in core height to $0.77 \mathrm{~m}$ will yield a sodium void worth of much less than $\$ 1.00$. Since fission gas pressure loadings calculated are minimal, the plenum regions were also reduced to lower friction through the assemblies and increase coolant flow. This provides a reduction in fuel and cladding operating temperatures. The higher power density core also requires high fuel burnup to maintain core rated power. To limit this, a modification in the specified ALMR fuel reload scheme that reduces fuel residency time is used. The peak burnup is now calculated to be approximately 19 at. $\%$. Although somewhat high, burnups of 20 at. 8 are supported in the literature.

\section{CONCLUSIONS}

Although nitride fuels historically have received less attention than other advanced fuels for LMRs, it is evident from the programs that are currently underway that this should no longer be the case. The development of nitride fuel systems is continuing with support of irradiation testing for both space reactor systems and proposed advanced LMRs throughout the world. The fabrication of nitride fuels appears feasible on a large scale, and compatibility with established reprocessing techniques should allow the integration of nitride fuels into existing fast reactor fuel cycles.

Nitride fuels combine many of the favorable properties of other fuel systems such as having high thermal conductivity similar to metal fuels with a high melting temperature typical of ceramic fuels. This combination of operational and safety characteristics can provide reactor systems with both design flexibility and enhanced performance. The pin designs proposed in this paper build on these characteristics to produce an economical and rugged (e.g., large steady-state operating margins) fuel pin concept. The results of conceptual performance analyses of nitride core designs exhibit good thermal performance and greatly reduce core sodium void worth without substantial impact on the core design. This reduction of sodium void reactivity may aid in passively mitigating the impacts of safety related transient events.

\section{ACKNOWLEDGMENTS}

The authors would like to gratefully acknowledge $R$. H. Webb for his numerous contributions to this project. This work was carried out under the auspices of the U.S. Department of Energy.

\section{REFERENCES}

1. A. A. BAUER, "Nitride Fuels: Properties and Potentials," Reactor Technology 15 (2) (1972).

2. A. E. DUBBERLEY, A. J. LIPPS, T. WU, P. M. MAGEE, "Designing for Passive Safety in the ALMR," Trans. of the 1990 International Fast Reactor Safety Meeting, Vol. 1, Snowbird, Utah (August 1990).

3. J. M. SIMMONS, J. A. LEARY, J. H. KITTEL, C. M. COX, "The U.S. Advanced LMFBR Fuels Development Program," in Advanced LMFBR Fuels, Topical Meeting Proc., Tuscon, Arizona (1977).

4. A. A. BAUER, P. CYBULSKIS, R. L. PETTY, N. S. DEMUTH, "Helium- and Sodium-Bonded Mixed-Nitride Fuel Performance," in Proc. of the International Conference on Fast Breeder Reactor Fuel Performance, Monterey, California (1979). 
5. J. W. HALES, B. J. MAKENAS, D. S. DUTT, "SP-100 Fuel Pin Irradiation Testing," Trans. Sixth Symposium on Space Nuclear Power Systems, held in Albuquerque, New Mexico, (1989).

6. R. B. MATTHEWS, "Overview of SP-100 Fuel Development Activities," in Trans. of the Seventh Symposium on Space Nuclear Power Systems, CONF900109, held in Albuquerque, New Mexico, (1990).

7. C. PRUNIER, P. BARDELLE, K. RICHTER, R. W. STRATTON, G. LEDERGERBER, "European Collaboration on Mixed Nitride Fuel, "Trans. of the ANS Winter Meeting, Washington, D.C. (1990).

8. M. F. TROYANOV, A. A. RINEYSKY, "The state of work on Fast Reactors in the USSR," presented at the 22nd Session of the the International Fast Reactor Working Group, Vienna, Austria (1989).

9. Y. ARIA, S. FUKUSHIMA, K. SHIOZAWA, M. HANDA, "Fabrication of (U,Pu)N Fuel Pellets," J. Nuc. Mater., 168 (1968).

10. C. GANGULY, P. V. HEGDE, A. K. SENGUPTA, "Status of (UPu) C and (UPu) N Fuel Development in BARC," in Advanced Fuel for Fast Breeder Reactors: Fabrication and Properties and Their Optimization, IAEA-TECDOC-466, International Atomic Energy Agency (1988).

11. R. B. MATTHEWS, K. M. CHIDESTER, C. W. HOTH, R. E. MASON, R. L. PETTY, "Fabrication and Testing of Nitride Fuel for Space Power Reactors," J. Nuc. Mater. 151 (1988).

12. H. BERNARD, P. BARDELLE, D. WARIN, "Fabrication of Uranium-Plutonium Mixed Nitride in an Oxide Line," Proc. Tech. Comm. Advanced Fuel for FBR, IAEA 43-51, International Atomic Energy Agency (1987).

13. R. B. MATTHEWS, R. J. HERBST, "Uranium-Plutonium Carbide Fuel for Fast Breeder Reactors, "Nuclear Technology 163 (1983).

14. HJ. MATZKE, H. BLANK, "Fuel Research and Basic Aspects of Fuel In-Pile Performance," J. Nuc. Mater. 166 (1989).

15. H. BLANK, "Specification and Characterization of Dense Fuels for Liquid Metal Cooled Fast Breeder Reactors," J. Nuc. Mater. 153 (1988).

16. W. F. LYON, R. B. BAKER, R. D. LEGGETT, "Performance Analysis of a Mixed Nitride Fuel System for an Advanced Liquid Metal Reactor," Trans. of the ANS Winter Meeting, Washington, D. C. (1990).

17. A. PADILLA, S. F. KESSLER, K. D. DOBBIN, A. E. WALTAR, "Fuel Aspects of Beyond Design Basis Event Analyses for the Fast Flux Test Facility," Trans. of the 1990 International Fast Reactor Safety Meeting, Snowbird, UT (1990).

18. K. D. DOBBIN, S. F. KESSLER, J. V. NELSON, R. P. OMBERG, S. R. GEDEON, "Sodium Void Reactivity Comparison for Advanced Liquid Metal Reactor Fuels," Trans. of the ANS Summer Meeting, Orlando, Florida (1991). 
Number of copies

OEESITE

1

U.S. Department of Energy= Headquarters

A. VanEcho

2

General Electric-Advanced

Nuclear Technology

6835 Via Del Oro, Box 530954

San Jose, California 95153-5354

E. L. Gluekler

P. M. Magee

2

Los Alamos National Laboratory

P.O. Box 1663, MS E505

Los Alamos, New Mexico 87545

R. B. Matthews

ONSITE

1

Pacific Northwest Laboratory

J. L. Ethridge

$P 8-34$

5

U.S. Department of Energy=

Richland Operations office

O. A. Farabee (4)

A6-55

R. A. Almquist

A6-55

15

Westinghouse Hanford Company
R. B. Baker
F. E. Bard
L5-01
A. E. Bridges
L5-01
K. D. Dobbin
L5-01
M. C. Druby
N2 -32
G. I. Fox
B3 -30
E. W. Gerber
L5-01
B. C. Gneiting
L5-62
J. M. Grover
L5-01
J. W. Hales
L $5-55$
L5-02
C. A. Hinman
$\mathrm{H} 0-33$
F. H. Huang
H5-67
G. D. Johnson
H $4-23$ 


\section{DISTRIBUTION (Cont'd)}

S. F. Kessler

$\mathrm{N} 2-32$

R. A. Karnesky

HO 0 -39

R. D. Leggett (2)

$\mathrm{H} 0-32$

D. M. Lucoff

N2 -34

W. F. Lyon III (5)

L $5-02$

B. J. Makenas

L5-02

J. V. Nelson

$\mathrm{N} 2-32$

R. P. Omberg

HO -40

A. Padilla

$\mathrm{H} 0-32$

A. L. Pitner

R. J. Puigh II

L5-01

$P$. K. Shen

L6-39

D. J. Swaim

HO -39

N2-51

A. E. Waltar

HO -32

J. D. Watrous

L5-60

R. H. Webb

L5-02

Document Distribution and

Processing (2)

L $8-15$

Information Release Administration

L8 -07 